\title{
MÉTODOS DE PREPARAÇÃo DE LACTONAS DE ANEL MÉDIO
}

Luiz S. Longo Junior ", Fernanda I. Bombonato e Helena M. C. Ferraz*

Instituto de Química, Universidade de S. Paulo, CP 26077, 05513-970 São Paulo - SP, Brasil

Recebido em 1/2/06; aceito em 20/4/06; publicado na web em 31/10/06

METHODS FOR THE PREPARATION OF MEDIUM RING LACTONES. There are several natural products bearing medium ring lactone moieties, which are those containing a ring size in the range of 8 to 11 members. This review intends to cover the last 10 years (1996-2005) of the literature concerning the synthesis of medium ring lactones.

Keywords: medium ring lactones; macrocycles; synthetic methods.

\section{INTRODUÇÃOO}

Anéis lactônicos de 8 a 11 membros - conhecidos como lactonas de anel médio - são unidades estruturais presentes em um variado número de produtos naturais, sendo, conseqüentemente, importantes alvos sintéticos ${ }^{1}$.

As principais metodologias para a construção de anéis médios são praticamente as mesmas utilizadas para anéis maiores, conforme pode ser visto em uma recente e interessantíssima revisão sobre métodos de macrolactonização ${ }^{2}$. Algumas revisões relacionadas com o tema que pretendemos abordar foram publicadas nos últimos anos, merecendo destaque as referentes à síntese de lactamas de anel médio ${ }^{3}$ e de anéis médios de 8 a 10 membros $^{4}$.

Como exemplos de lactonas naturais contendo um anel de 8 membros, podemos citar as octalactinas A e B (Figura 1), isoladas de actinomicetos do gênero Streptomyces, coletados na superfície de corais da costa mexicana. Tais lactonas apresentaram atividade citotóxica significativa contra células de melanomas e de tumor de cólon ${ }^{5}$.

Da esponja marinha Halichondria okadai, coletada na costa do Japão, foram isoladas as lactonas de 9 membros halicholactona e neo-halicholactona ${ }^{6,7}$ (Figura 1).

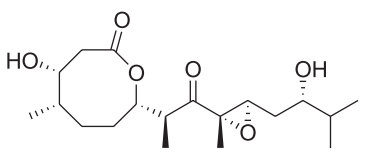

Octalactina A

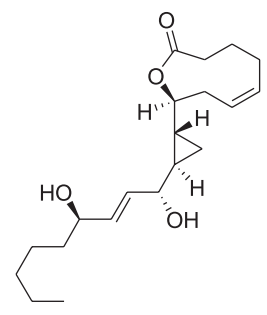

Halicholactona

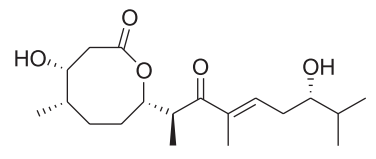

Octalactina B

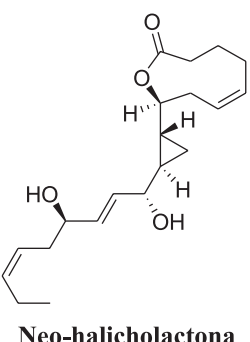

Figura 1. Lactonas naturais de 8 e 9 membros

"Endereço atual: Universidade Federal de São Paulo, Diadema - SP

*e-mail: hmferraz@iq.usp.br
Lactonas de 10 membros - denominadas nonanolídeos ${ }^{3}$ - são mais abundantes na natureza que as lactonas médias de outros tamanhos. Em 1996, Drager et al. ${ }^{8}$ publicaram uma revisão sobre os vários nonanolídeos de origem natural, enfocando sua ocorrência, diversidade estrutural, biogênese e aspectos farmacológicos.

Há poucos anos, Rivero-Cruz et al..$^{9,10}$ isolaram do fungo Phoma herbarum três lactonas de 10 membros, que chamaram de herbaruminas (Figura 2). Estas lactonas mostraram atividade fitotóxica significativa na inibição da germinação e do crescimento de mudas de Amaranthus hypochondriacus, o que as torna potenciais herbicidas.

Outro exemplo importante de nonanolídeos é representado pela família das decarestrictinas ${ }^{11}$, que apresentaram significativo efeito inibitório na biossíntese do colesterol. Tais lactonas foram isoladas de extratos obtidos em processos de fermentação promovidos por espécies do gênero Penicillium. As estruturas de algumas decarestrictinas encontram-se na Figura 2.<smiles>CCC[C@H](OC(=O)CCCC=CC(O)[C@@H](C)O)[C@@H](O)CC</smiles>

Herbarumina I<smiles>CCC[C@H](OC(=O)[C@H](O)CCC/C=C/C(O)[C@@H](C)O)[C@@H](C)O</smiles>

Herbarumina II<smiles>CC1CC[C@H](O)/C=C/[C@H](O)CC(=O)O1</smiles>

Decarestrictina $\mathbf{C}_{2}$<smiles>CCC[C@H](CC(O)/C=C/CCCCC(=O)O)OC</smiles>

Herbarumina III
Decarestrictina $\mathbf{A}_{1}$

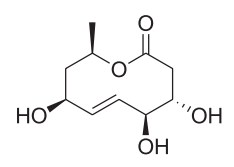

Decarestrictina D

Figura 2. Lactonas naturais de 10 membros

Recentemente, Singh et al. ${ }^{12}$ isolaram de um extrato de Aspergillus sp. três lactonas de 11 membros, às quais deram o nome de asperciclídeos (Figura 3).

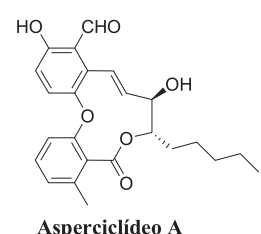

Asperciclídeo A

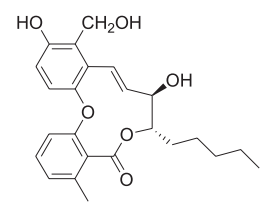

Asperciclídeo B

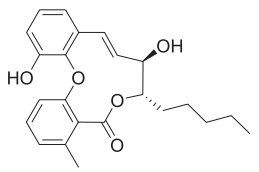

Asperciclídeo C

Figura 3. Lactonas naturais de 11 membros 
É conhecido que compostos de anel médio, inclusive lactonas, são mais difíceis de se preparar por reações de ciclização que seus homólogos inferiores ou superiores ${ }^{13,14}$. Tal dificuldade reside no fato de que a ciclização é desfavorecida tanto por fatores entrópicos quanto por fatores entálpicos, como discutido por Illuminati e Mandolini ${ }^{15}$. Estes autores mediram a velocidade de formação de lactonas de 3 a 23 membros, a partir de ácidos $\omega$-bromo-alcanóicos, e verificaram que bons rendimentos são conseguidos na obtenção de lactonas de 3 a 7 e de 13 a 18 membros, onde a reação intramolecular é predominante. Por outro lado, com os ácidos que levariam às lactonas de 8 a 12 membros, a reação predominante é a polimerização (reação intermolecular, portanto), uma vez que a velocidade de formação das respectivas lactonas é muito baixa. Para a lactona de 9 membros, a velocidade é praticamente zero.

A ciclização de $\omega$-hidróxi-ácidos foi investigada por vários grupos de pesquisa, utilizando diferentes metodologias ${ }^{16-19}$. O ácido 8hidróxi-octanóico, por ex., forneceu a lactona de 9 membros em rendimentos que variam de 0,8 a $18 \%$, enquanto que o produto principal, em todas as condições testadas ${ }^{16-19}$, foi o dímero de 18 membros. Rendimentos similares foram obtidos para lactonas médias de outros tamanhos, enquanto que rendimentos bem superiores foram conseguidos para anéis maiores. Estes dados confirmam a dificuldade de obtenção de lactonas de anel médio, sobretudo as de 8 e 9 membros, por reações de ciclização.

$\mathrm{Na}$ tentativa de solucionar os problemas encontrados nas ciclizações clássicas, várias outras estratégias sintéticas foram então desenvolvidas, e podem ser consultadas no extenso trabalho de revisão publicado por Rousseau ${ }^{1}$, em 1995.

Posterior à mencionada revisão, merece destaque o trabalho desenvolvido pelo grupo de Yamamoto $^{20}$, em que o trifluorometanossulfonato de escândio foi usado como um eficiente catalisador ácido para a acilação de álcoois com anidridos ou para a esterificação de álcoois com ácidos carboxílicos, na presença do anidrido p-nitro-benzóico. O método mostrou-se especialmente útil para a lactonização de ácidos carboxílicos $\omega$-hidroxilados, fornecendo lactonas de 7 a 17 membros em ótimos rendimentos.

Nosso interesse na síntese de lactonas de anel médio teve início há poucos anos, quando estávamos investigando a oxidação de um éter bicíclico com $\mathrm{RuO}_{4}$ e, diferentemente do esperado, obtivemos como produto uma ceto-lactona de 9 membros - este assunto será tratado com detalhes no item apropriado (clivagem oxidativa de biciclos).

Desta maneira, decidimos efetuar uma revisão bibliográfica sobre os métodos de preparação de lactonas de anel médio, cobrindo os últimos 10 anos, ou seja, o período posterior à revisão de Rousseau. Dos anos anteriores a 1996, apenas serão citadas as referências essenciais à compreensão do texto. Esta revisão está dividida em 6 itens, baseados no tipo de reação envolvida: reações de lactonização; ciclizações radicalares; reações de metátese; clivagem oxidativa de biciclos; rearranjo de Claisen; reações de Diels-Alder.

\section{REAÇÕES DE LACTONIZAÇÃO}

Em 1998, Homsi e Rousseau ${ }^{21}$ relataram os resultados obtidos na preparação de lactonas através da iodociclização eletrofílica de ácidos carboxílicos $\omega$-insaturados, promovida pelo hexafluorofosfato de iodo bis-colidina. Os autores verificaram que a introdução de substituintes na cadeia do ácido - o que acarreta em uma restrição conformacional - leva à obtenção de lactonas de anel médio, especialmente as de 8 membros, em rendimentos bastante satisfatórios. Alguns exemplos encontram-se no Esquema 1.

Mais tarde, os autores determinaram as proporções entre a for-

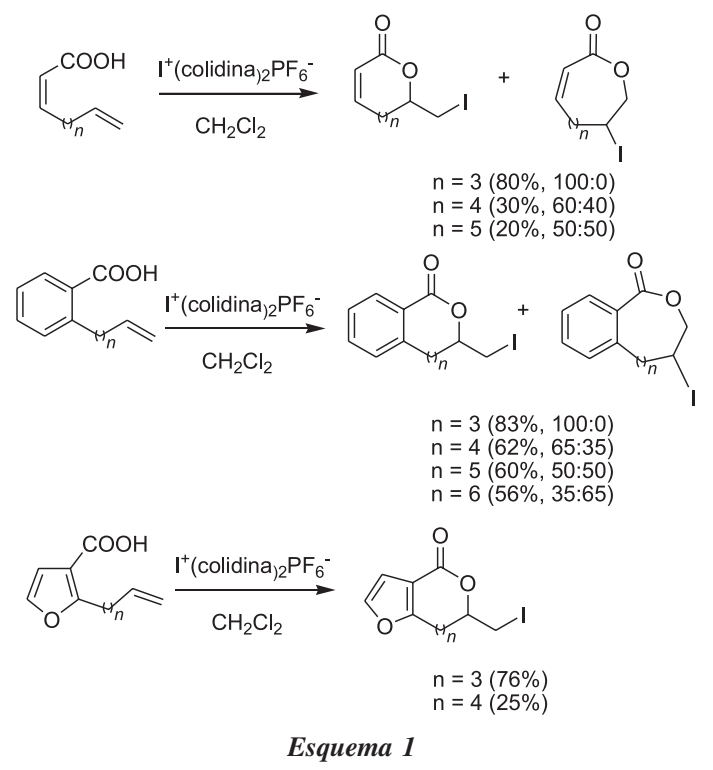

mação dos produtos de ciclização exo e endo (lactonas de 7 a 20 membros) na iodo- e na bromo-lactonização de ácidos carboxílicos $\omega$-insaturados ${ }^{22}$.

A iodolactonização de derivados fenólicos forneceu misturas regioisoméricas de lactonas de 9 e 10 membros, em rendimentos moderados ${ }^{23}$. Um exemplo é mostrado no Esquema 2.

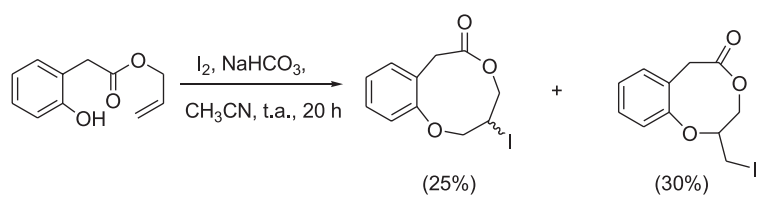

Esquema 2

Lactonizações de hidróxi-ácidos facilitadas pela ativação do ácido carboxílico ${ }^{16-20,24}$ têm sido usadas como etapa-chave na síntese de inúmeros macrolídeos, além de lactonas de anel médio, como nos exemplos apresentados a seguir.

$\mathrm{Na}$ estratégia de Yamaguchi ${ }^{16}$, a reação de um ácido carboxílico $\omega$-hidroxilado com o cloreto de 2,4,6-triclorobenzoíla leva à formação de um anidrido misto contendo um bom grupo de partida, o que facilita a lactonização.

Critcher et al. ${ }^{25}$ aplicaram essa estratégia na primeira síntese assimétrica da halicholactona e da neohalicholactona, concluída em 1997 (Esquema 3).
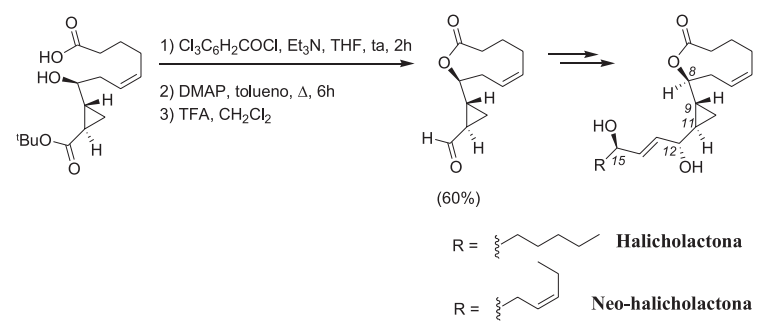

Esquema 3

O aldeído intermediário do Esquema 3 foi também sintetizado por Mohapatra e Datta ${ }^{26}$, o que representa uma síntese formal das duas lactonas acima mencionadas.

Estratégia semelhante foi utilizada pelos mesmos autores ${ }^{27}$ para sintetizar o segmento ciclopropano-lactona $\left(\mathrm{C}_{1}-\mathrm{C}_{12}\right)$ das solandelactonas, substâncias de origem marinha isoladas na costa coreana $^{28}$. A etapa de lactonização está mostrada no Esquema 4. 


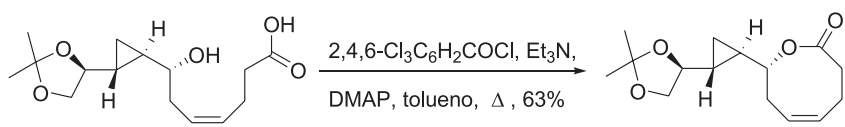

Esquema 4

A lactonização de Yamaguchi ${ }^{16}$ foi também aplicada à síntese total da (-)-decarestrictina $\mathrm{C}_{2}$, conforme resumido no Esquema $5^{29}$.

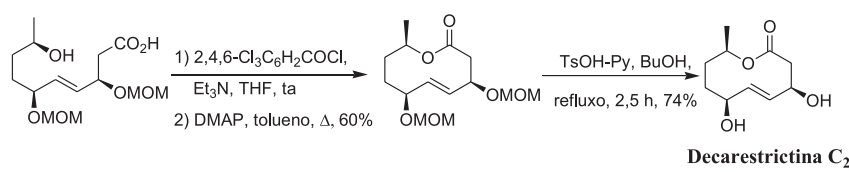

Esquema 5

Recentemente, Kobayashi et al. ${ }^{30}$ relataram uma síntese estereosseletiva da decarestrictina $\mathrm{D}$, utilizando ainda o mesmo reagente de lactonização (Esquema 6). Neste artigo, os autores discutem a influência de diferentes grupos protetores das hidroxilas na eficiência da reação, sendo que o melhor rendimento (40\%) foi obtido quando se usou o grupo metóximetil éter (MOM).

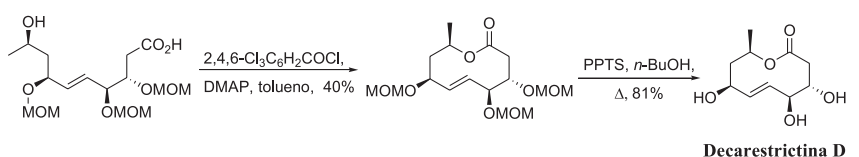

Esquema 6

Recentemente, foram descritas duas sínteses do microcarpalídeo, uma lactona de 10 membros isolada em $2001^{31}$. Ambas as sínte$\operatorname{ses}^{32,33}$ envolvem a lactonização de Yamaguchi. A etapa chave da síntese de Ishigami et al. ${ }^{32}$ está mostrada no Esquema 7.
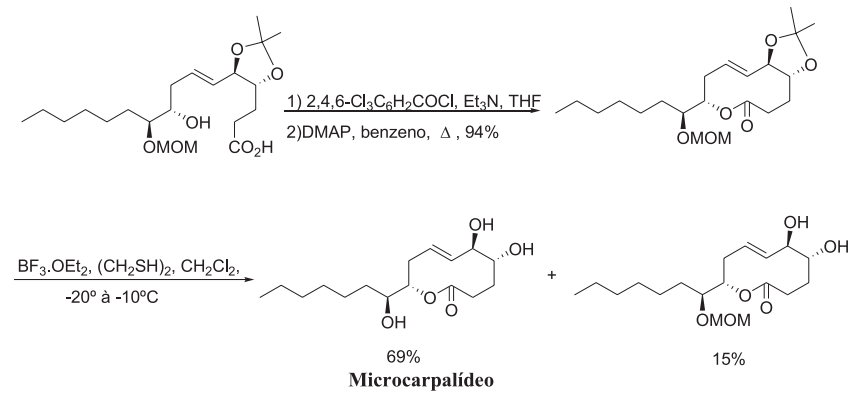

Esquema 7

Uma modificação do método - emprego da diisopropil-etilamina (DIPEA) em vez da trietilamina - foi utilizada por Sabino e Pilli ${ }^{34}$ na síntese total da (+)-herbarumina I (Esquema 8).

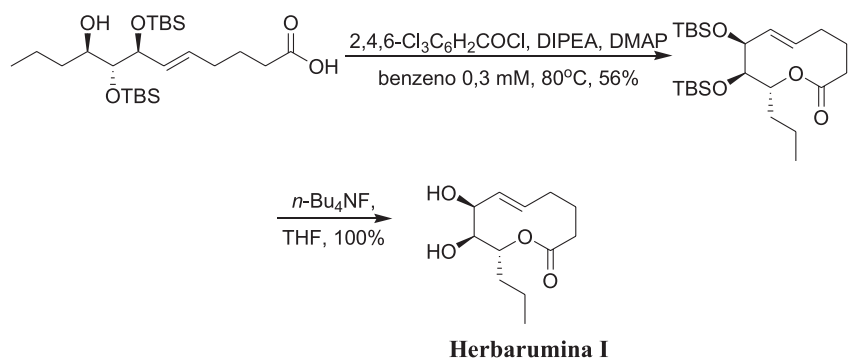

Esquema 8

Várias lactonas de 8 membros - precursoras de octalactinas foram preparadas por Buszek et al. ${ }^{35}$ (Esquema 9), utilizando o método desenvolvido por Corey e Nicolaou ${ }^{17}$. Neste método, a reação de um hidróxi-ácido com dissulfeto de 2,2'-dipiridina leva à ativação tanto da função ácido quanto da hidroxila, através de uma transferência de próton observada no intermediário reacional. Os autores também discutem a influência dos vários grupos presentes na cadeia lateral do hidróxi-ácido no tempo reacional e nos parâmetros cinéticos da lactonização.
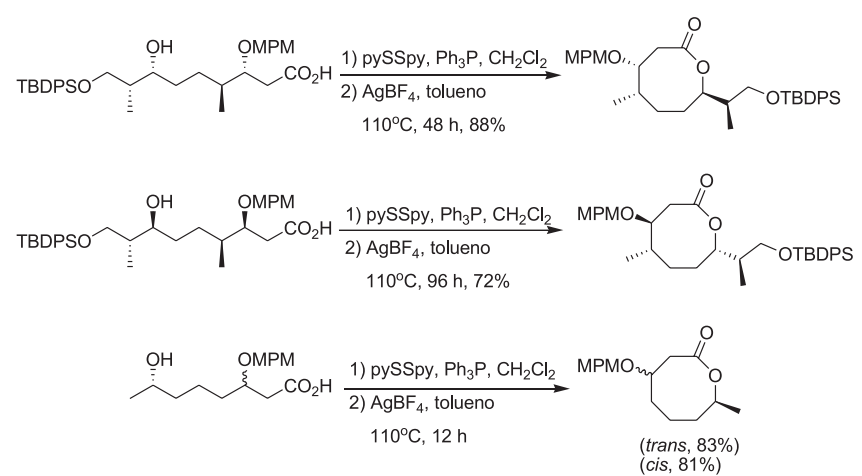

Esquema 9

O método de Corey-Nicolaou ${ }^{17}$ foi aplicado com sucesso por Andrus e Shih $^{36}$ na síntese total da decarestrictina D (compare com os Esquemas 6 e 25), também conhecida como tucolídeo (Esquema 10).

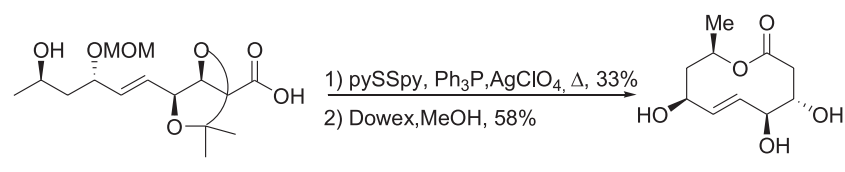

Tucolídeo ou

Decarestrictina D

Esquema 10

O emprego de dicicloexil-carbodiimida (DCC) para a ativação do ácido carboxílico e de DMAP.HCl como agente doador de prótons - importante na preservação da função éster (ou lactona) nas condições de alta diluição que são utilizadas nestes protocolos - foi desenvolvido por Boden e $\mathrm{Keck}^{24}$.

Esta estratégia foi utilizada por Andrus e Argade $^{37}$ na preparação de uma lactona precursora da (+)-octalactina A. Os autores testaram a reação em presença de DCC e de cloreto de etil-dimetilaminopropil-carbodiimida (EDCI), obtendo a lactona desejada em 73 e $81 \%$ de rendimento, respectivamente (Esquema 11).

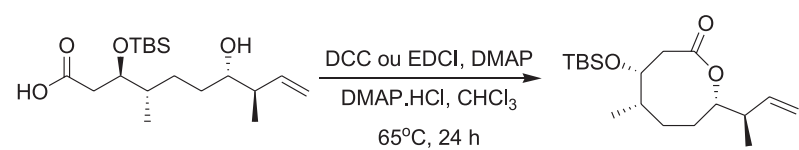

( $73 \%$, para uso de DCC ( $81 \%$, para uso de EDCl)

Esquema 11

Fujiwara et al..$^{38}$ também aplicaram esta metodologia na preparação de uma lactona de 9 membros, a partir de um hidróxi-ácido (Esquema 12).

Posteriormente, os mesmos autores ${ }^{39}$ usaram esta reação para preparar uma lactona intermediária na síntese total do éter cíclico (+)-obtusenina (Esquema 13).

Em 1998, Shiina et al. ${ }^{40}$ efetuaram a lactonização de uma mistura racêmica de hidróxi-ácidos, em um trabalho visando à síntese 
<smiles>CCC(O)CC/C=C\CCC(=O)O</smiles>

Esquema 12

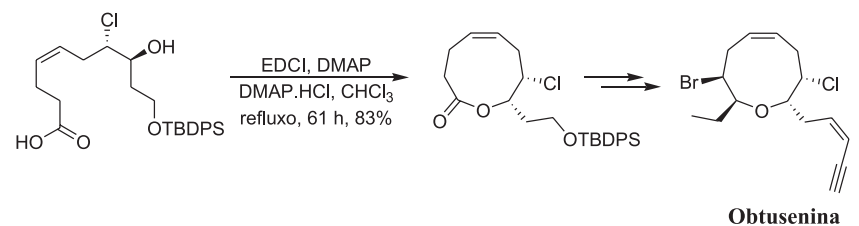

Esquema 13

total do cefalosporolídeo D e a determinação de suas estereoquímicas absoluta e relativa. Assim, as lactonas contendo as hidroxilas protegidas foram obtidas em $67 \%$ de rendimento. $\mathrm{Na}$ etapa de lactonização foi utilizado o anidrido tríflico e, como catalisador ácido, o triflato de háfnio (Esquema 14).

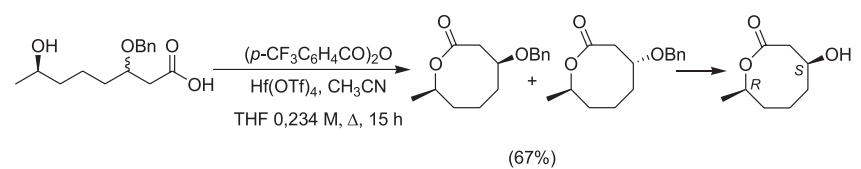

Esquema 14

Em trabalho recente, Shiina ${ }^{41}$ discute o emprego de anidridos benzóicos diferentemente substituídos e de $\mathrm{TiCl}_{2}\left(\mathrm{ClO}_{4}\right)_{2}$ como catalisador na lactonização de diversos ácidos carboxílicos.

A utilização do anidrido metil-nitro benzóico (MNBA), na presença de um catalisador básico, para a esterificação ou a lactonização de ácidos carboxílicos, foi também estudada por Shiina et al. ${ }^{42}$ Dentre as lactonas sintetizadas, encontram-se vários macrolídeos (anéis de 12 ou mais membros), além da unidade lactônica de 8 membros presente nas octalactinas A e B (Esquema 15).

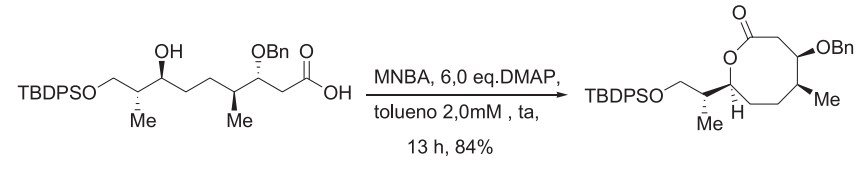

Esquema 15

Em um trabalho cujo principal enfoque foi a síntese de hidróxiácidos precursores de benzolactonas de anel médio, Métay et al. ${ }^{43}$ empregaram o método de Yamamoto $^{20}$ para obtenção das lactonas. (Esquema 16).

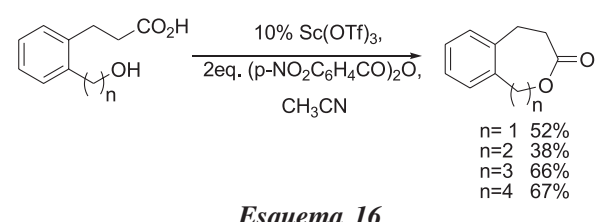

Esquema 16

A lactonização de Mitsunobu ${ }^{19}$, em que se usam trifenilfosfina e dietilazadicarboxilato (DEAD), foi utilizada por diversos grupos de pesquisa para sintetizar a unidade tioéter-lactona de 9 membros presente no antibiótico griseoviridina.

Assim, partindo de um derivado da L-(S)-cisteína, Ardisson et $a l{ }^{44}$ sintetizaram um intermediário avançado para a síntese da 8- epi-griseoviridina. As principais etapas consistiram da sequência: lactonização de Mitsunobu, hidroestanilação de Magriotis; carbonilação de Heck (Esquema 17).

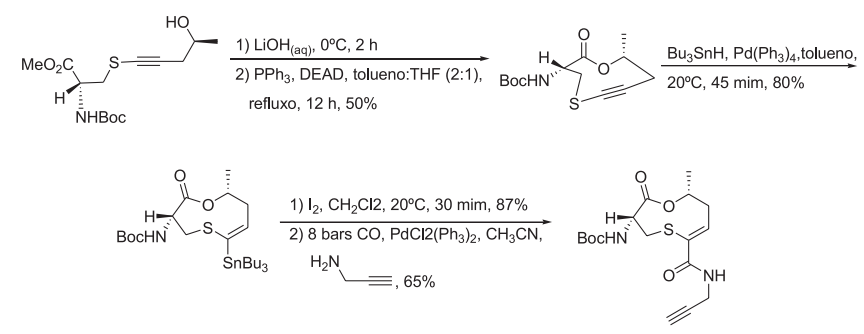

Esquema 17

A obtenção da unidade lactônica correspondente à entgriseoviridina, juntamente com um isômero, foi relatada pelo mesmo grupo ${ }^{45}$. A abordagem utilizada consistiu de uma ciclização redutiva de um dissulfeto intermediário. Este, por sua vez, foi sintetizado a partir da L-NHBoc-cistina (Esquema 18).

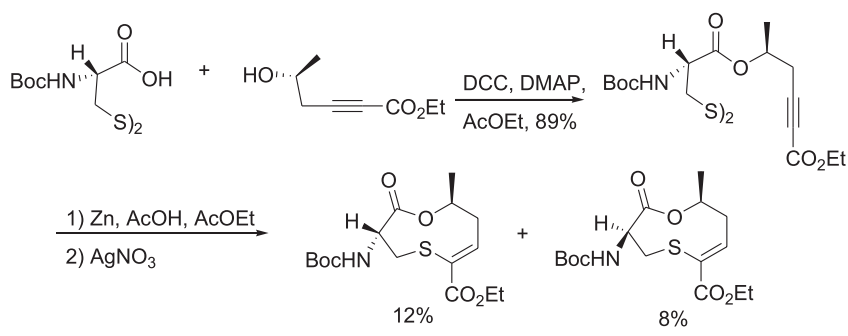

Esquema 18

Marcantoni et al. ${ }^{46}$ utilizaram um derivado da D-(R)-cisteína para preparar um intermediário-chave que foi submetido às condições de Mitsunobu modificadas ${ }^{47}$ (Esquema 19).

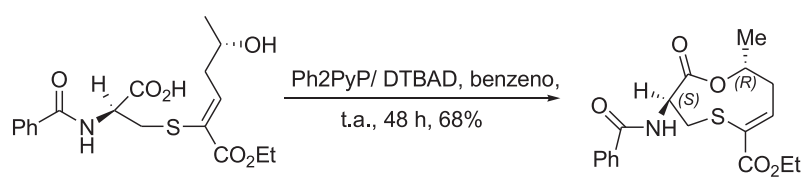

Esquema 19

O mesmo intermediário acima mostrado foi sintetizado por outro grupo ${ }^{48}$ e submetido às condições clássicas de Mitsunobu, fornecendo o anel de 9 membros em 58\% de rendimento.

$\mathrm{Na}$ síntese total da griseoviridina, Dvorak et al. ${ }^{49}$ também empregaram as mesmas condições para a etapa de ciclização, conforme Esquema 20.

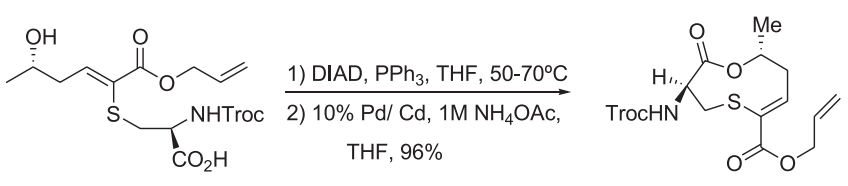

Esquema 20

\section{CICLIZAÇÕES RADICALARES}

Em 1996, Russell e Li ${ }^{50}$ publicaram um estudo sobre a ciclização radicalar 8-endo-trig de acrilatos de 4-pentenila promovida por $t$ $\mathrm{BuHgI} / \mathrm{KI}$, levando a lactonas de 8 membros. A reação se processa através da formação de organomercuriais, que podem ser isolados 
ou ciclizados por fotoestimulação em presença de dissulfeto de difenila, fornecendo as lactonas desejadas em rendimentos moderados (Esquema 21).

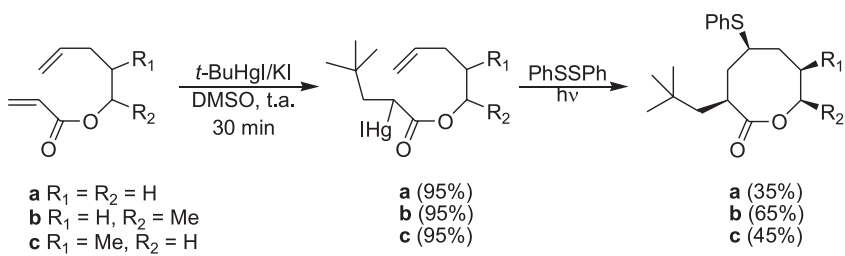

Esquema 21

Blake et al. ${ }^{51}$ estudaram a ciclização radicalar seqüencial de acrilatos de iodo-alquenila promovida por $\mathrm{Bu}_{3} \mathrm{SnH} / \mathrm{AIBN}$, a qual levou a lactonas bicíclicas em rendimentos razoáveis. Exemplos ilustrativos encontram-se no Esquema 22.

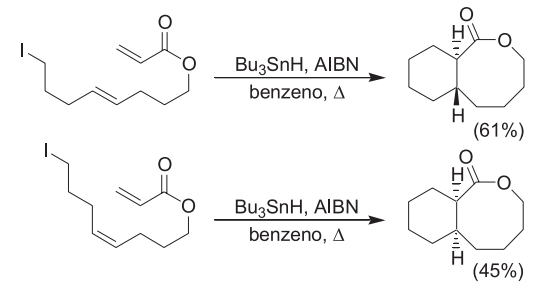

Esquema 22

Em 1998, Lee et al ${ }^{52}$ relataram seus resultados a respeito da ciclização 8-endo-trig de bromoacetatos e bromopropionatos de 4 alquenila. Assim, a reação destes substratos com $\mathrm{Bu}_{3} \mathrm{SnH} / \mathrm{AIBN}$ em condições de diluição elevada levou, em todos os casos, aos respectivos heptanolídeos, juntamente com os produtos acíclicos oriundos da redução da ligação C-Br (Esquema 23).

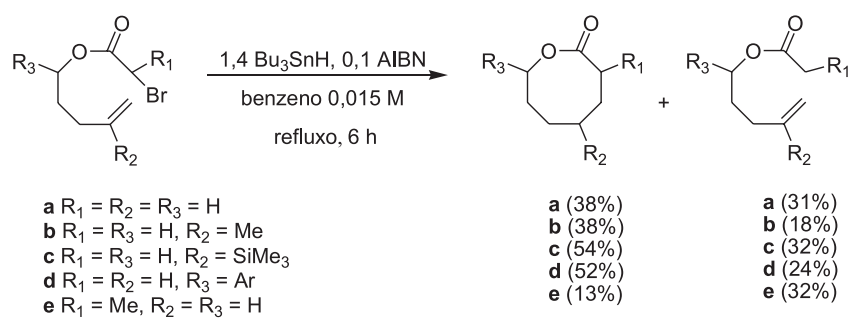

Esquema 23

A reação de bromoacetatos de alquenila homólogos não forneceu os produtos de ciclização esperados - que seriam as lactonas de 7, 9, 10 e 16 membros. Nestes casos, foi observada apenas a redução da ligação C-Br.

Os precursores de radicais hipofosfito de N-etilpiperidina (EPHP) e óxido de dietilfosfina (DEPO) mostraram-se eficientes para promover a ciclização de \pm -bromo-amidas e ésteres insaturados, com formação de lactonas e lactamas ${ }^{53}$. O Esquema 24 mostra um exemplo.

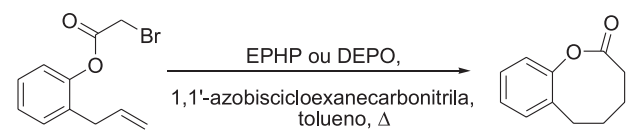

Esquema 24

A ciclização de tricloroacetatos insaturados promovida por complexos de $\mathrm{Cu}(\mathrm{I})$ e $\mathrm{Fe}(\mathrm{II})$ foi estudada por Campo et al. ${ }^{54,55}$. O catalisador foi preparado in situ pela reação de $\mathrm{CuCl}$ e $\mathrm{FeCl}_{2}$ com os ligantes L1, L2 e L3 e a ciclização radicalar levou às lactonas de anel médio mostradas na Tabela 1 .

Tabela 1. Ciclização radicalar de tricloroacetatos insaturados ${ }^{\mathrm{a}}$

\begin{tabular}{llll}
\hline Substrato & Produto & Catalisador $^{\mathrm{b}}$ & Rendimento \\
\hline & & $\mathrm{CuCl} . \mathbf{L 1}$ & $99 \%$ \\
& $\mathrm{FeCl}_{2} . \mathbf{L} 2$ & $46 \%$ \\
$\mathrm{C}$ & $\mathrm{CuCl} . \mathbf{L 3}$ & $90 \%$
\end{tabular}

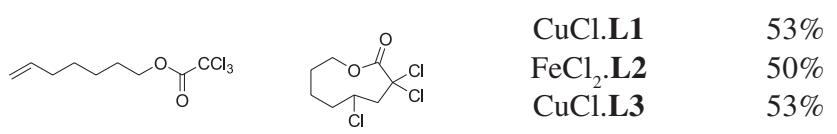

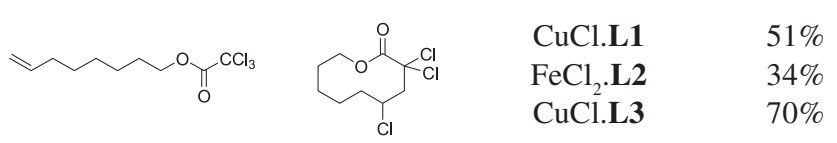

${ }^{a}$ Reagentes e Condições: $1 \mathrm{mmol}$ do substrato, 0,3 a $10 \mathrm{~mol} \%$ de catalisador, 1,2-dicloroetano $(0,2 \mathrm{M}), 80{ }^{\circ} \mathrm{C}$;

${ }^{b}$ ligantes:

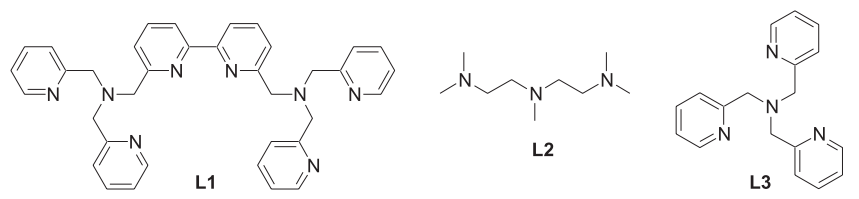

A ciclização radicalar de iodoacetatos e iodopropionatos de 4pentenila, através da sua fotoestimulação na presença de $\mathrm{Bu}_{3} \mathrm{SnSnBu}_{3}$, também levou às $\gamma$-butirolactonas correspondentes em excelentes rendimentos ${ }^{56}$.

Outra estratégia sintética que vem sendo usada com sucesso na preparação de lactonas de anel médio é a reação de Nozaki-HiyamaKishi, onde um iodeto vinílico reage com um aldeído na presença de $\mathrm{CrCl}_{2}$ e $\mathrm{NiCl}_{2}$, com a formação de uma nova ligação carbonocarbono.

Pilli et al. ${ }^{57,58}$ aplicaram esta metodologia na síntese total da (-)decarestrictina D (Esquema 25).

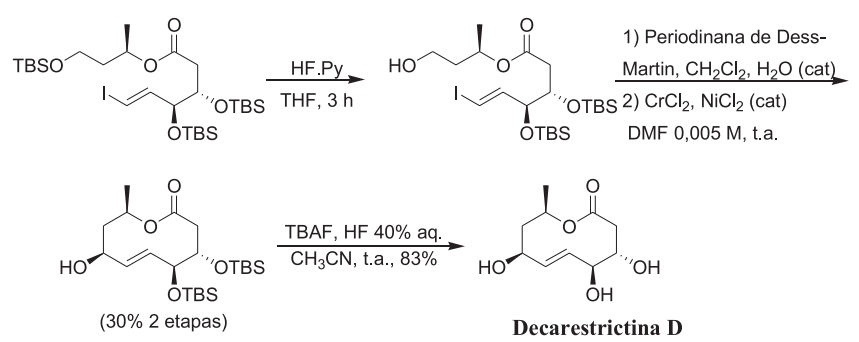

Esquema 25

Pilli et al. ${ }^{59}$ também utilizaram a reação de Nozaki-HiyamaKishi na primeira síntese total do (-)-aspinolídeo, uma lactona natural isolada de culturas de Aspergillus ochraceus. Neste caso, o substrato inicial levou a uma mistura das lactonas de 10 membros, na proporção de 2:3, respectivamente (Esquema 26). Entretanto, após separação cromatográfica, a lactona contendo o centro $8 R$ pôde ser convertida a $8 S$, usando a inversão de Mitsunobu. a esterificação da hidroxila em C8, seguida da desproteção das hidroxilas em $\mathrm{C} 4$ e C5, forneceu o (-)-aspinolídeo desejado. 


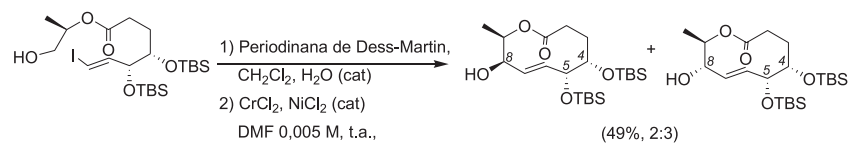

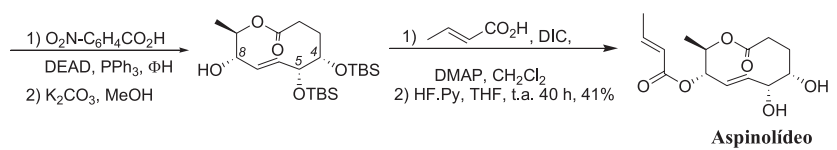

\section{Esquema 26}

$\mathrm{O}$ mesmo grupo ${ }^{60}$ também investigou a influência do padrão de substituição e dos grupos protetores na seletividade facial na reação de Nozaki-Hiyama-Kishi para a construção de lactonas de 10 membros.

\section{REAÇÕES DE METÁTESE}

A formação de ligações carbono-carbono gerando sistemas cíclicos pode ser realizada não somente por reações de ciclização, como também por reações de metátese de olefinas, onde ligações carbono-carbono insaturadas, presentes em um precursor acíclico, são rearranjadas na presença de um catalisador de metal de transição apropriado $^{61-65}$. Esta estratégia vem sendo amplamente utilizada na construção de sistemas cíclicos de anel médio, conforme pode ser visto a seguir ${ }^{66}$.

Kalesse et al. ${ }^{67,68}$ prepararam lactonas de 10 membros como intermediárias na síntese total da epotilona $\mathrm{A}$. A reação de metátese, utilizando o catalisador de Grubbs $\left(\mathrm{PCy}_{3}\right)_{2} \mathrm{Cl}_{2} \mathrm{Ru}=\mathrm{CHPh}$, levou a uma mistura dos isômeros $E$ e $Z$ das lactonas, na proporção de 1:12 (Esquema 27).

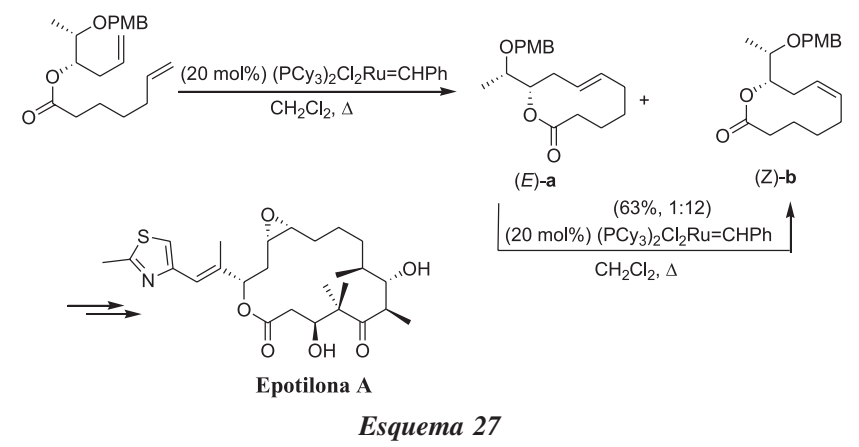

Baba et al.$^{69}$ realizaram a síntese total da halicholactona, utilizando o mesmo catalisador para a reação de metátese olefínica (Esquema 28).

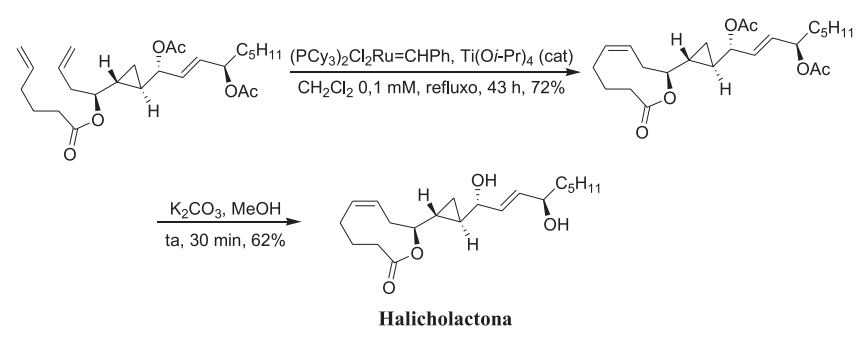

Esquema 28

Fürstner et $a l{ }^{70,71}$ utilizaram a reação de metátese na primeira síntese total das herbaruminas I e II . A metátese do substrato olefínico utilizando um catalisador de primeira geração forneceu preferencialmente o isômero cinético $(E)$, em 69\% de rendimento. Quando se utilizou o catalisador de segunda geração, foi obtido exclusivamente o isômero termodinâmico (Z), em $86 \%$ de rendimento (Esquema 29).

Segundo os autores, o catalisador de segunda geração é capaz

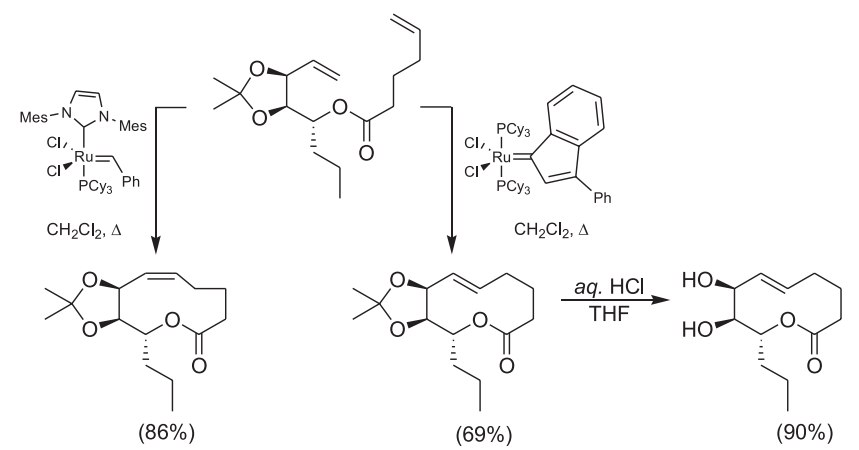

Herbarumina I

Esquema 29

de isomerizar a dupla ligação que se forma. Assim, a proporção $E / Z$ não é controlada cineticamente e, sim, é resultado de um equilíbrio químico, o qual favorece o produto termodinâmico $(Z)$.

Analogamente, a metátese de outra olefina com o catalisador de primeira geração forneceu preferencialmente a lactona de 10 membros com dupla ligação $E$, a qual levou à herbarumina II por desproteção das hidroxilas em C2, C7 e C8 (Esquema 30).

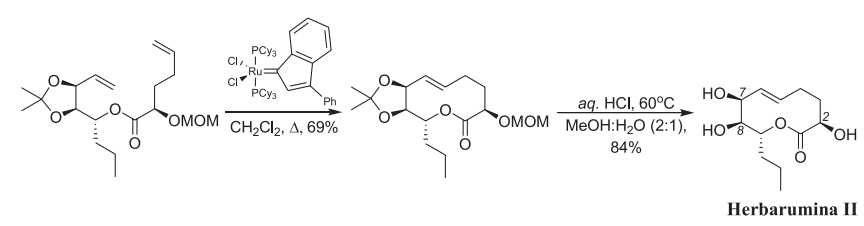

Esquema 30

Recentemente, o mesmo grupo ${ }^{72}$ empregou uma reação de metátese como etapa chave na primeira síntese total do asperciclídeo C (Esquema 31).

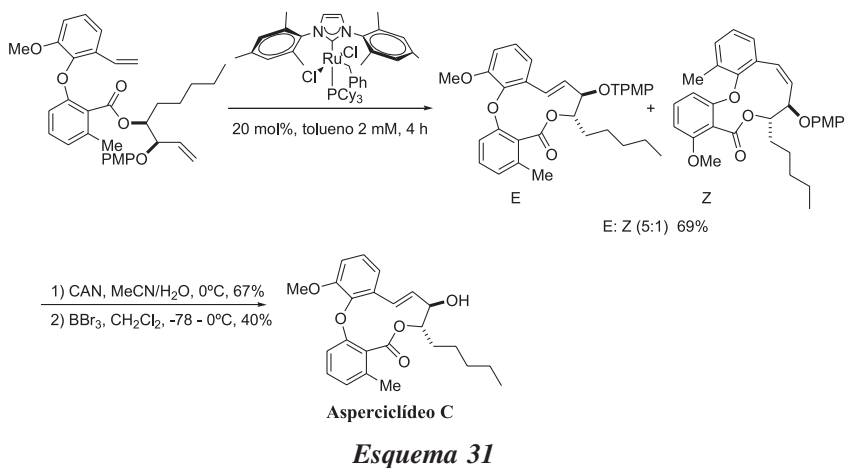

A reação da olefina abaixo com o catalisador de Grubbs $\left(\mathrm{PCy}_{3}\right)_{2} \mathrm{Cl}_{2} \mathrm{Ru}=\mathrm{CHPh}$ forneceu uma lactona de 8 membros, que foi utilizada como intermediário-chave na síntese da octalactina $\mathrm{A}^{73}$ (Esquema 32).

$$
\text { MPMO... }
$$

Esquema 32

Esta estratégia também foi utilizada por diferentes grupos na síntese total do microcarpalídeo ${ }^{74-79}$.

Assim, o grupo de Carda e Marco ${ }^{74}$ efetuou a reação de metátese olefínica, obtendo uma mistura das lactonas $E$ e $Z$, na proporção de $2: 1$, respectivamente, da qual a lactona $(E)$ pôde ser isolada por 
coluna cromatográfica. Deve-se ressaltar que esta foi a primeira síntese total do microcarpalídeo (Esquema 33).

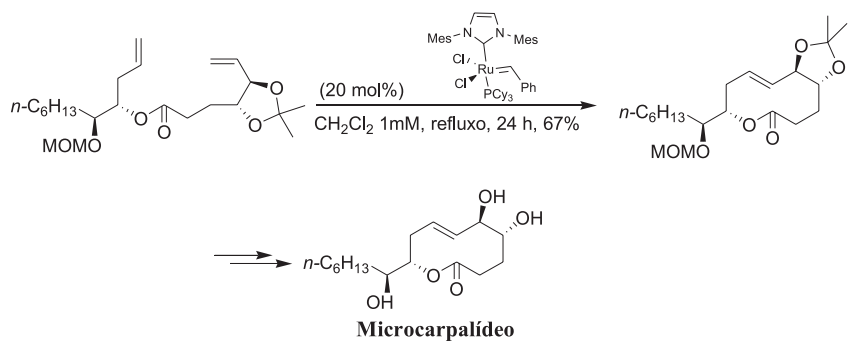

Esquema 33

O mesmo grupo de pesquisa publicou, recentemente ${ }^{75}$, outra síntese total do (-)-microcarpalídeo, de maneira bastante semelhante. Neste artigo, os autores também relatam a síntese da (+)letaloxina e comprovam que sua configuração absoluta é a mesma da (+)-pinolidoxina, desfazendo uma dúvida que vinha persistindo na literatura desde o isolamento desta última, há mais de 10 anos.

Gurjar et $a l .{ }^{76}$ obtiveram o microcarpalídeo por uma reação de metátese seguida de desproteção das hidroxilas (Esquema 34).

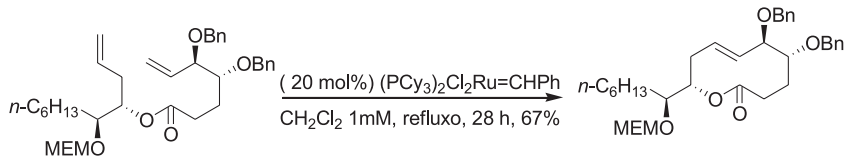

$$
\underset{0^{\circ} \mathrm{C}, 30 \mathrm{~min}, 76 \%}{\stackrel{\mathrm{CH}_{2}}{\mathrm{C} \mathrm{Cl}_{2}}} \text { Microcarpalídeo }
$$

Esquema 34

Utilizando abordagens bastante semelhantes, Davoli et al. ${ }^{77,78} \mathrm{e}$ Chavan et al. ${ }^{79}$ também realizaram sínteses totais do (-)microcarpalídeo.

Dando continuidade a trabalhos anteriores ${ }^{26,27}$, o grupo de Mohapatra utilizou reações de metátese olefínica para obtenção do segmento ciclopropano-lactona presente nas solandelactonas ${ }^{80}$ e nas halicho- e neo-halicholactona ${ }^{81}$.

\section{CLIVAGEM OXIDATIVA DE BICICLOS}

Hemicetais bicíclicos são os substratos mais utilizados para a clivagem oxidativa de ligações carbono-carbono saturadas, a qual leva a lactonas de anel médio. Esta estratégia foi primeiramente aplicada em 1966 por Borowitz et al. ${ }^{82}$, utilizando $\mathrm{Pb}(\mathrm{OAc})_{4}$ como agente oxidante. Entretanto, vários outros métodos podem ser encontrados na literatura ${ }^{83}$.

Em 1996, Hanaki et al. ${ }^{84}$ prepararam iodolactonas de 10 membros, através da clivagem oxidativa radicalar de hemicetais promovida por $\mathrm{PhI}(\mathrm{OAc})_{2} / \mathrm{I}_{2}$, na presença de luz (Esquema 35).

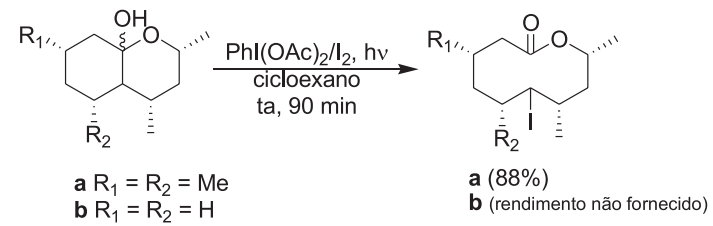

Esquema 35

Os autores também prepararam ceto-lactonas, através da ozonólise da mistura dos éteres vinílicos bicíclicos mostrados no Esquema 36.

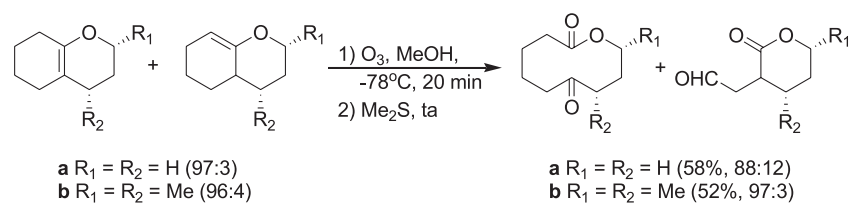

Esquema 36

Martel et al. ${ }^{85}$ utilizaram a clivagem fotoquímica promovida por $\mathrm{PhI}(\mathrm{OAc})_{2} / \mathrm{I}_{2}$ na preparação de iodolactonas de 10 membros, em um estudo visando a síntese de nonanolídeos da família das decarestrictinas (Esquema 37).

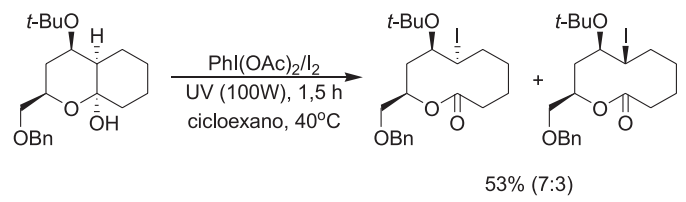

Esquema 37

O grupo de Posner aplicou a reação de fragmentação oxidativa de anel, também mediada por iodo hipervalente, para sintetizar uma série de lactonas de 8 a 10 membros $^{86}$, e de 9 a 12 membros $^{87}$. A sequiência estudada, que tem como etapa-chave a bis-sililação de cicloalquenonas, permitiu a síntese do (-)-foracantolídeo $\mathrm{J}^{87}$, resumida no Esquema 38.

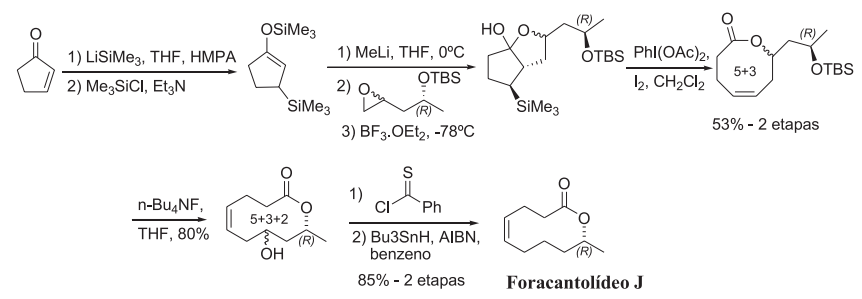

Esquema 38

Conforme mencionado no início desta revisão, a reação de um $\beta$-hidróxi-éter cíclico com $\mathrm{RuO}_{4}$ levou à inesperada formação de uma ceto-lactona de 9 membros, em vez do produto de oxidação esperado (Esquema 39).

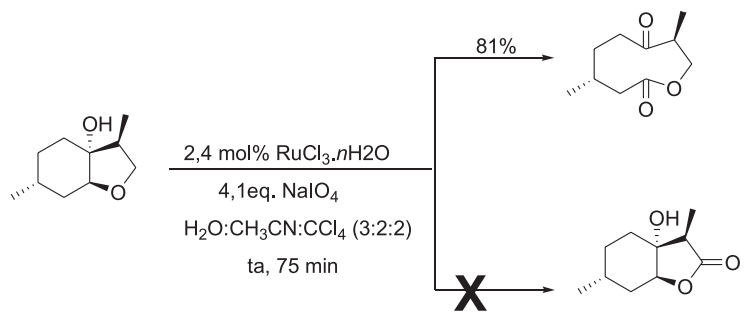

Esquema 39

A reação é efetuada em condições catalíticas, em um sistema bifásico de solventes, onde o $\mathrm{RuO}_{4}$ é gerado in situ a partir de $\mathrm{RuCl}_{3} \cdot n \mathrm{H}_{2} \mathrm{O}$ e $\mathrm{NaIO}_{4}$, usado como co-oxidante. Tal resultado levounos a estender este estudo a outros substratos ${ }^{88}$, conforme resumido na Tabela 2. É importante mencionar que estas reações são extremamente limpas, fornecendo as ceto-lactonas com elevado grau de pureza.

Embora o mecanismo da oxidação de $\beta$-hidróxi éteres pelo $\mathrm{RuO}_{4}$ ainda não esteja claro, a presença da hidroxila na junção dos anéis parece desempenhar um papel importante na sua quimiosseletividade, determinando a oxidação preferencial do carbono 
Tabela 2. Clivagem oxidativa promovida por $\mathrm{RuO}_{4}{ }^{\mathrm{a}}$

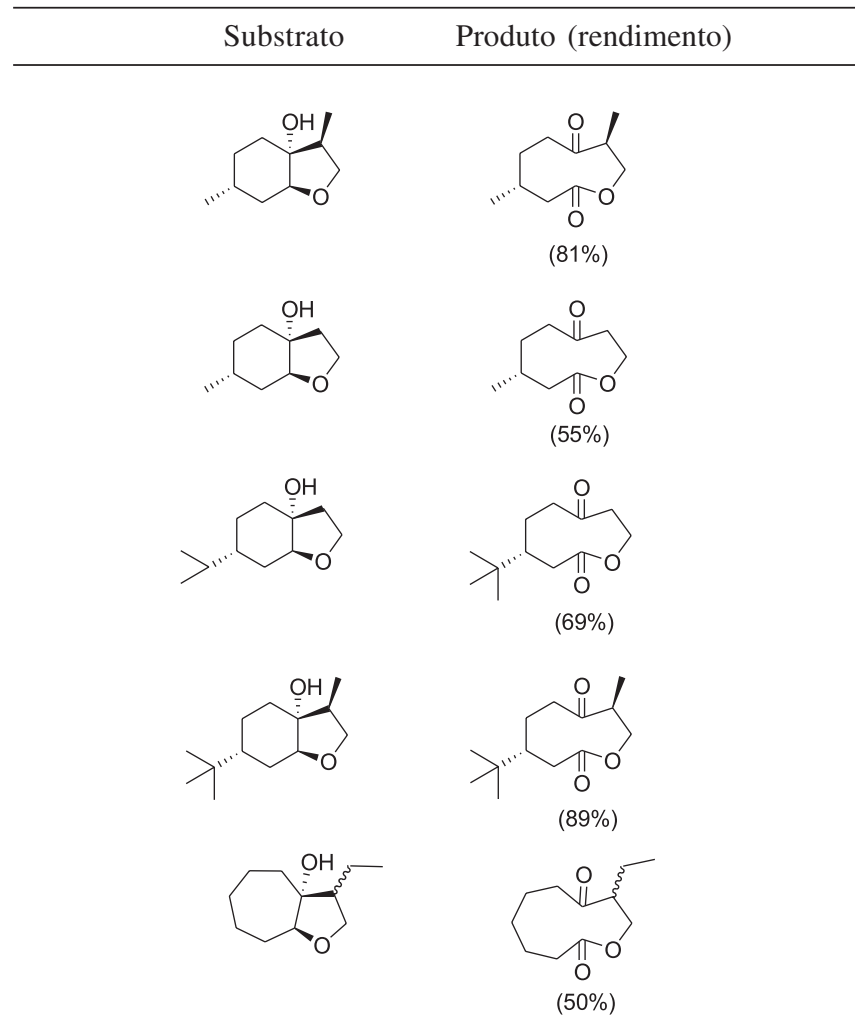

${ }^{a}$ Reagentes e condições: $2,4 \mathrm{~mol} \% \mathrm{RuCl}_{3} \cdot n \mathrm{H}_{2} \mathrm{O}, 4,1$ eq. $\mathrm{NaIO}_{4}$, $\mathrm{H}_{2} \mathrm{O} / \mathrm{CCl}_{4} / \mathrm{CH}_{3} \mathrm{CN}(3: 2: 2)$, ta, $75 \mathrm{~min}$; ${ }^{b} 90 \mathrm{~min}$.

terciário, ao contrário da esperada oxidação de um carbono secundário. Segundo Bakke e Frohaug ${ }^{89}$, que estudaram o mecanismo da oxidação de hidrocarbonetos e éteres pelo $\mathrm{RuO}_{4}$, a ordem de reatividade para a oxidação de éteres seria: $\mathrm{CH}_{2}>\mathrm{CH} \gg \mathrm{CH}_{3}$.

Recentemente, Silva et al..$^{90}$ relataram a obtenção de uma lactona de 10 membros, através de ozonólise de um derivado da $\beta$-lapachona (Esquema 40).

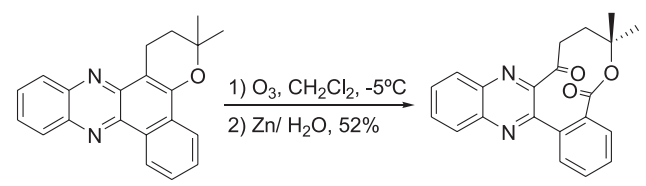

Esquema 40

\section{REARRANJO DE CLAISEN}

Uma das mais elegantes maneiras de se construir uma nova ligação C-C é através de um rearranjo sigmatrópico [3,3], chamado rearranjo de Claisen ${ }^{91,92}$.

O rearranjo de ceteno-acetais vinil- e alquenil-substituídos, preparados in situ a partir de fenil seleno-acetais ou de carbonatos, vem sendo bastante explorado na síntese de lactonas de anel médio, pelo grupo de Holmes e Burton ${ }^{93-98}$.

Em 1997, foi relatada ${ }^{93}$ a síntese assimétrica da (+)-laurencina, um éter cíclico de 8 membros. A lactona intermediária foi preparada através de duas rotas diferentes: (a) rearranjo de Claisen de um ceteno-acetal, seguido de $\alpha$-hidroxilação; e (b) lactonização de Yamaguchi de um hidróxi ácido, seguida da desproteção da hidroxila em C3 (Esquema 41).

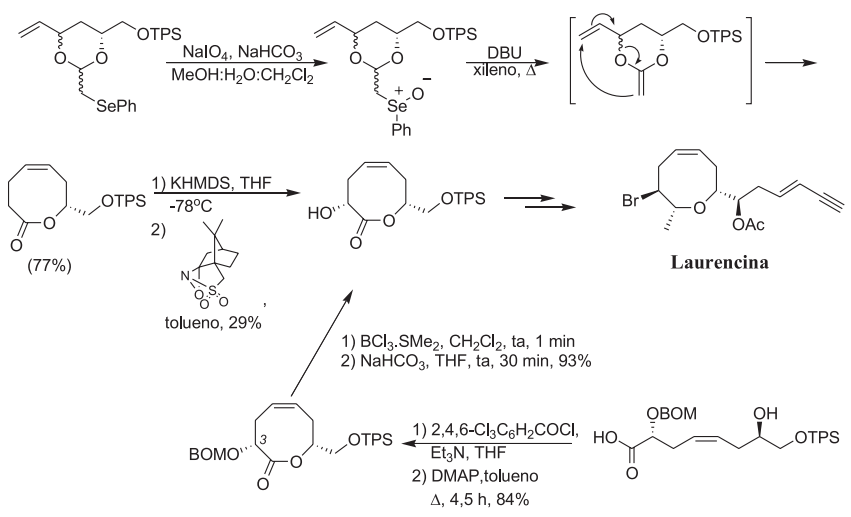

Esquema 41

Mais tarde ${ }^{94}$, foram sintetizadas lactonas assimétricas, através do rearranjo de Claisen de ceteno-acetais alquenil-substituídos, preparados in situ pela eliminação de selenóxido dos respectivos selenoacetais quirais (Esquema 42).

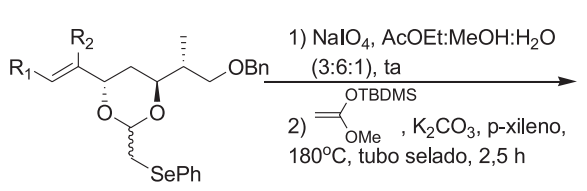

Esquema 42

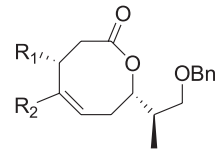

$\mathrm{R}_{1}=\mathrm{R}_{2}=\mathrm{H}(64 \%)$ $\mathrm{R}_{1}=\mathrm{H}, \mathrm{R}_{2}=\mathrm{Me}(64 \%)$ $\mathrm{R}_{1}=\mathrm{Me}, \mathrm{R}_{2}=\mathrm{H}(36 \%)$ $R_{1}=R_{2}=\operatorname{Me}(23 \%)$

Esta estratégia também foi aplicada com sucesso na síntese de lactonas bicíclicas ${ }^{95}$, conforme exemplos mostrados no Esquema 43.

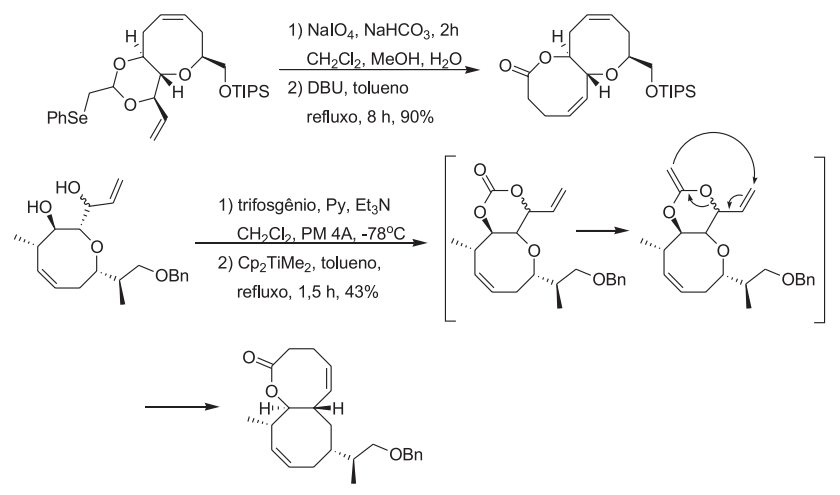

Esquema 43

Segundo os autores, a geração de ceteno-acetais a partir de carbonatos é um método alternativo à eliminação de selenóxidos, a qual apresenta como problema a formação de disseleneto de difenila ( $\mathrm{PhSeSePh}$, capaz de converter o selenóxido intermediário ao seleno-acetal de partida. Isto leva a rendimentos baixos na geração do ceteno-acetal e à necessidade do uso de condições reacionais drásticas (aquecimento em tudo selado).

O grupo também relatou seus estudos sobre a reação seqüencial de olefinação/rearranjo de Claisen de carbonatos cíclicos ${ }^{96,97}$. A olefinação de carbonatos cíclicos de 6 e 7 membros, promovida pelo dimetiltitanoceno, levou à geração in situ dos respectivos ceteno-acetais, os quais, por sua vez, forneceram lactonas de 8 e 9 membros, através do rearranjo sigmatrópico [3,3] (Esquema 44). Uma aplicação da metodologia acima descrita à síntese das octalactinas A e B foi recentemente descrita pelo grupo ${ }^{98}$. 


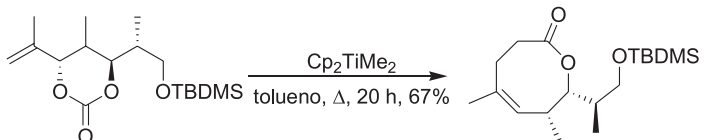

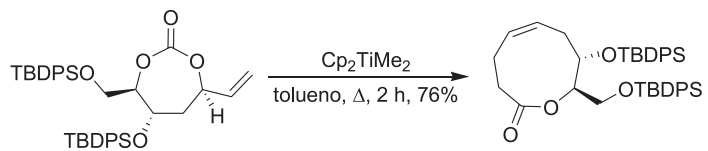

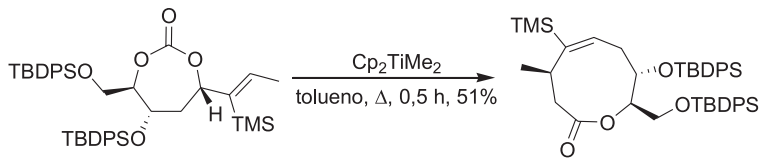

Esquema 44

\section{REAÇÕES DE DIELS-ALDER}

Em 1996, o grupo de Maddaluno ${ }^{99}$ efetuou a reação intramolecular de Diels-Alders de alguns trienos, utilizando três solventes diferentes (tolueno, benzonitrila e decaidronaftaleno). Misturas de oxalactonas trans e cis foram obtidas em rendimentos moderados e proporções variadas. Um exemplo é apresentado no Esquema 45.
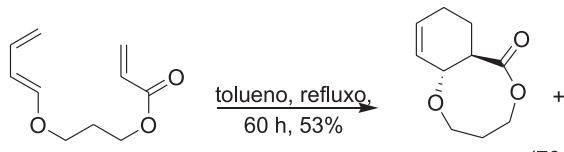

(70: 30

\section{Esquema 45}

Mais tarde os autores estenderam esta metodologia à preparação de lactonas de 8 membros mais funcionalizadas ${ }^{100}$. A cicloadição intramolecular [4+2] de um trieno contendo os grupos metílicos em cis levou à formação da lactona de junção trans como único diastereoisômero, enquanto que esta estereosseletividade não foi observada para o trieno com as metilas em trans (Esquema 46).

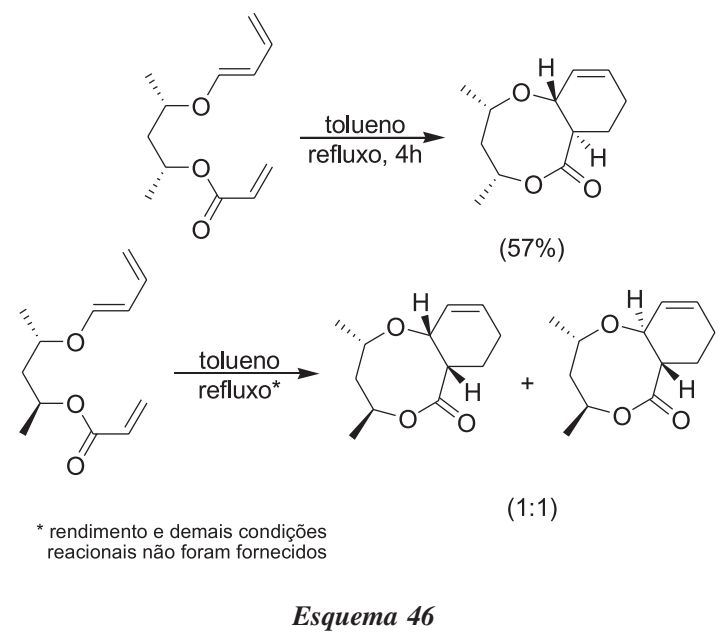

Recentemente, em um trabalho voltado para a síntese de carboaçúcares, o mesmo grupo ${ }^{101}$ preparou uma série de lactonas de 9 membros, através da sequência generalizada no Esquema 47.

\section{CONCLUSÕES}

Das diversas metodologias existentes para a síntese de lactonas de anel médio, a lactonização promovida pela ativação da função

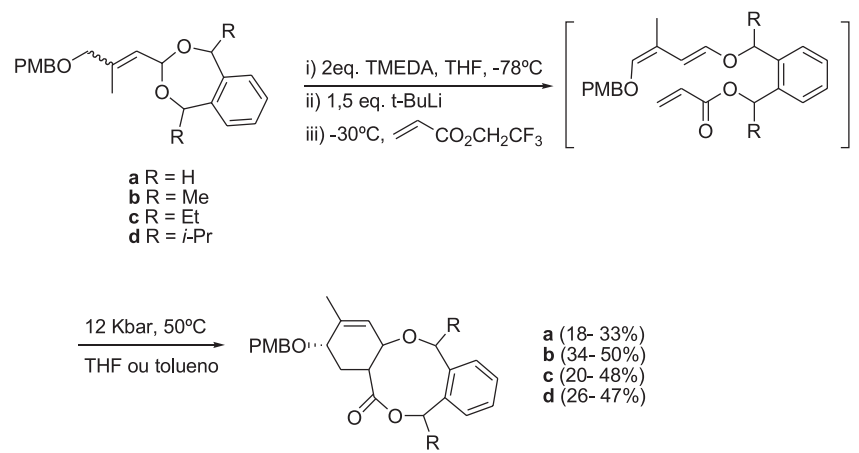

Esquema 47

ácido carboxílico continua sendo a mais utilizada. Conforme já mencionado no início deste artigo, uma extensa revisão sobre o emprego da macrolactonização de ácidos carboxílicos ativados na síntese total de produtos naturais foi recentemente publicada ${ }^{2}$. Por outro lado, no que se refere ao rearranjo de Claisen e às reações de Diels-Alder, deve-se notar que são métodos de aplicação pontual, normalmente restritos a um único tipo de substrato. Já os $\beta$-hidróxi-éteres cíclicos mostraram-se bastante promissores ${ }^{102}$ como substratos para a síntese de lactonas de anel médio, através da clivagem oxidativa promovida por $\mathrm{RuO}_{4}$. Finalmente, é importante ressaltar que há uma tendência crescente do emprego da metátese olefínica em lactonizações, assunto este que talvez já mereça uma revisão à parte.

\section{AGRADECIMENTOS}

Ao colega L. F. Silva Jr., pela constante ajuda na busca de novas referências e, sobretudo, pelo estímulo durante a redação deste artigo.

À FAPESP, ao CNPq e à CAPES, pelos auxílios financeiros e bolsas.

\section{REFERÊNCIAS}

1. Rousseau, G.; Tetrahedron 1995, 51, 2777.

2. Parenty, A.; Moreau, X.; Campagne, J.M.; Chem. Rev. 2006, 106, 911.

3. Nubbemeyer, U.; Top. Curr. Chem. 2001, 216, 125.

4. Nubbemeyer, U.; Eur. J. Org. Chem. 2001, 1801.

5. Tapiolas, D. M.; Roman, M.; Fenical, W.; Stout, T. J.; Clardy, J.; J. Am. Chem. Soc. 1991, 113, 4682.

6. Niwa, H.; Wakamatsu, K.; Yamada, K.; Tetrahedron Lett. 1989, 30, 4543.

7. Kigoshi, H.; Niwa, H.; Yamada, K.; Stout, T. J.; Clardy, J.; Tetrahedron Lett. 1991, 32, 2427.

8. Dräger, G.; Kirschning, A.; Thiericke, R.; Zerlin, M.; Nat. Prod. Rep. 1996, 13,365 .

9. Rivero-Cruz, J. F.; Garcia-Aguirre, G.; Cerda-Garcia-Rojas, C. M.; Mata, R.; Tetrahedron 2000, 56, 5337.

10. Rivero-Cruz, J. F.; Garcia-Aguirre, G.; Cerda-Garcia-Rojas, C. M.; Mata, R.; J. Nat. Prod. 2003, 66, 511.

11. Grabley, S.; Hammann, P.; Hutter, K.; Kirsch, R.; Kluge, H.; Thiericke, R.; Mayer, M.; Zeeck, A.; J. Antibiot. 1992, 45, 1176.

12. Singh, S. B.; Jayasuriya, H.; Zink, D. L.; Polishook, J. D.; Dombrowski, A. W.; Zweerink, H.; Tetrahedron Lett. 2004, 45, 7605.

13. Molander, G. A.; Acc. Chem. Res. 1998, 31, 603.

14. Yet, L.; Chem. Rev. 2000, 100, 2963.

15. Illuminati, G.; Mandolini. L.; Acc. Chem. Res. 1981, 14, 95.

16. Inanaga, J.; Hirata, K.; Saeki, H.; Katsuki, T.; Yamaguchi. M.; Bull. Chem. Soc. Jpn. 1979, 52, 1989.

17. Corey, E. J.; Nicolaou, K. C.; J. Am. Chem. Soc. 1974, 96, 5614.

18. Mukaiyama, T.; Usui, M.; Saigo, K.; Chem. Lett. 1976, 49.

19. Kurihara, T.; Nakajima, Y.; Mitsunobu, O.; Tetrahedron Lett. 1976, 2455.

20. Ishihara, K.; Kubota, M.; Kurihara, H.; Yamamoto, H.; J. Org. Chem. 1996, $61,4560$.

21. Homsi, F.; Rousseau, G.; J. Org. Chem. 1998, 63, 5255.

22. Roux, M. C.; Paugam, R.; Rousseau, G.; J. Org. Chem. 2001, 66, 4304.

23. Brown, D. P.; Krishnamurthy, L.; Heterocycles 2004, 63, 1185. 
24. Boden, E. P.; Keck, G. E.; J. Org. Chem. 1985, 50, 2394.

25. Critcher, D. J.; Connolly, S.; Wills, M.; J. Org. Chem. 1997, 62, 6638.

26. Mohapatra, D. K. ; Datta, A.; J. Org. Chem. 1998, 63, 642.

27. Varadarajan, S.; Mohapatra, D. K.; Datta, A.; Tetrahedron Lett. 1998, 39, 1075.

28. Seo, Y.; Cho, K. W.; Rho, J. R.; Shin, J.; Kwon, B. M.; Bok, S. H.; Song, J. I.; Tetrahedron 1996, 52, 10583.

29. Arai, M.; Morita, N.; Aoyagi, S.; Kibayashi, C.; Tetrahedron Lett. 2000, 41,1199 .

30. Kobayashi, Y.; Asano, M.; Yoshida, S.; Takeuchi, A.; Org. Lett. 2005, 7, 1533.

31. Ratnayake, A. S.; Yoshida, W. Y.; Mooberry, S. L.; Hemsheidt, T.; Org. Lett. 2001, 3, 3479.

32. Ishigami, K.; Watanabe, H.; Kitahara, T.; Tetrahedron 2005, 61, 7546.

33. Kumar, P.; Naidu, S. V. J.; J. Org. Chem. 2005, 70, 4207.

34. Sabino, A. A.; Pilli, R. A.; Tetrahedron Lett. 2002, 43, 2819.

35. Buszek, K. R.; Jeong, Y.; Sato, N.; Still, P. C.; Muiño, P. L.; Ghosh, I.; Synth. Commun. 2001, 31, 1781.

36. Andrus, M. B.; Shih, T. L.; J. Org. Chem. 1996, 61, 8780.

37. Andrus, M. B.; Argade, A. B.; Tetrahedron Lett. 1996, 37, 5049.

38. Fujiwara, K.; Tsunashima, M.; Awakura, D.; Murai, A.; Chem. Lett. 1997, 665.

39. Fujiwara, K.; Awakura, D.; Tsunashima, M.; Nakamura, A.; Honma, T.; Murai, A.; J. Org. Chem. 1999, 64, 2616.

40. Shiina, I.; Fukuda, Y.; Ishii, T.; Fujisawa, H.; Mukaiyama, T.; Chem. Lett. 1998, 831 .

41. Shiina, I.; Tetrahedron 2004, 60, 1587.

42. Shiina, I.; Kubota, M.; Oshiumi, H.; Hashizume, M.; J. Org. Chem. 2004, 69, 1822.

43. Métay, H.; Léonel, E.; Sulpice-Gayllet, C.; Nédélec, J. Y.; Synthesis 2005, 1682.

44. Kuligowski, C.; Bezzenine-Lafollée, S.; Chaume, G.; Mahuteau, J.; Barrière, J. C.; Bacqué, E.; Pancrazi, A.; Ardisson, J.; J. Org. Chem. 2002, 67, 4565.

45. Chaume, G.; Kuligowski, C.; Bezzenine-Lafollée, S.; Ricard, L.; Pancrazi, A.; Ardisson, J.; Synthesis 2004, 3029.

46. Marcantoni, E.; Massaccesi, M.; Petrini, M.; Bartoli, G.; Bellucci, M. C.; Bosco, M.; Sambri, L.; J. Org. Chem. 2000, 65, 4553.

47. Kiankarimi, M.; Lowe, R.; McCarthy, J. R.; Whitten, J. P.;Tetrahedron Lett. 1999, 40, 4497.

48. Moreau, X.; Campagne, J. M.; J. Org. Chem. 2003, 68, 5346.

49. Dvorak, C. A.; Schmitz, W. D.; Poon, D. J.; Pryde, D. C.; Lawson, J. P.; Amos, R. A.; Meyers, A. I.; Angew. Chem., Int. Ed. 2000, 39, 1664

50. Russel, G. A.; Li, C.; Tetrahedron Lett. 1996, 37, 2557.

51. Blake, A. J.; Hollingworth, G. J.; Pattenden, G.; Synlett 1996, 643.

52. Lee, E.; Yoon, C. H.; Lee, T. H.; Kim, S. Y.; Ha, T. J.; Sung, Y. S.; Park, S. H.; Lee, S.; J. Am. Chem. Soc. 1998, 120, 7469.

53. Lang, S.; Corr, M.; Muir, N.; Khan, T. A.; Schonebeck, F.; Murphy, J. A.; Payne, A. H.; Williams, A. C.; Tetrahedron Lett. 2005, 46, 4027.

54. Campo, F.; Lastecouères, D.; Verlhac, J. B.; Chem. Commun. 1998, 2117.

55. Campo, F.; Lastecouères, D.; Verlhac, J. B.; J. Chem. Soc., Perkin Trans. I 2000, 575.

56. Wang, J.; Li, C.; J. Org. Chem. 2002, 67, 1271

57. Pilli, R. A.; Victor, M. M.; Tetrahedron Lett. 1998, 39, 4421.

58. Pilli, R. A.; Victor, M. M.; J. Braz. Chem. Soc. 2001, 12, 373.

59. Pilli, R. A.; Victor, M. M.; Meijere, A.; J. Org. Chem. 2000, 65, 5910.

60. Pilli, R. A.; Victor, M. M.; Tetrahedron Lett. 2002, 43, 2815.

61. Grubbs, R. H.; Chang, S.; Tetrahedron 1998, 54, 4413

62. Furstner, A.; Angew. Chem., Int. Ed. 2000, 39, 3012.

63. Trnka, T. M.; Grubbs, R. H.; Acc. Chem. Res. 2001, 34, 18.

64. Connon, S. J.; Blechert, S.; Angew. Chem., Int. Ed. 2003, 42, 1900.

65. Frederico, D.; Brocksom, U.; Brocksom, T. J.; Quim. Nova 2005, $28,692$.
66. Maier, M. E.; Angew. Chem., Int. Ed. 2000, 39, 2073.

67. Gerlach, K.; Quitschalle, M.; Kalesse, M.; Synlett 1998, 1108.

68. Kalesse, M.; Quitschalle, M.; Claus, E.; Gerlach, K.; Pahl, A.; Meyer, H. H.; Eur. J. Org. Chem. 1999, 2817.

69. Baba, Y.; Saha, G.; Nakao, S.; Iwata, C.; Tanaka, T.; Ibuka, T.; Ohishi, H.; Takemoto, Y.; J. Org. Chem. 2001, 66, 81.

70. Furstner, A.; Radkowski, K.; Chem. Commun. 2001, 671.

71. Furstner, A.; Radkowski, K.; Wirtz, C.; Goddard, R.; Lehmann, C. W.; Mynott, R.; J. Am. Chem. Soc. 2002, 124, 7061.

72. Furstner, A.; Muller, C.; Chem. Commun. 2005, 5583.

73. Buszek, K. R.; Sato, N.; Jeong, Y.; Tetrahedron Lett. 2002, 43, 181

74. Murga, J.; Falomir, E.; Garcia-Fortanet, J.; Carda, M.; Marco, J. A.; Org. Lett. 2002, 4, 3447.

75. Garcia-Fortanet, J.; Murga, J.; Falomir, E.; Carda, M.; Marco, J. A.; J. Org. Chem. 2005, 70, 9822.

76. Gurjar, M. K.; Nagaprasad, R.; Ramana, C. V.; Tetrahedron Lett. 2003, 44, 2873.

77. Davoli, P.; Spaggiari, A.; Castagnetti, L.; Prati, F.; Org. Biomol. Chem. 2004, 2, 38.

78. Davoli, P.; Fava, R.; Morandi, S.; Spaggiari, A.; Prati, F.; Tetrahedron 2005, $61,4427$.

79. Chavan, S. P.; Praveen, C.; Tetrahedron Lett. 2005, 46, 1939.

80. Mohapatra, D. K.; Yellol, G. S.; Arkivoc 2003 (ix) 21.

81. Mohapatra, D. K.; Durugkar, K. A.; Arkivoc 2004 (i) 146.

82. Borowitz, I. J.; Gonis, G.; Kelsey, R.; Rapp, R.; Williams, G. J.; J. Org. Chem. 1966, 31, 3032 .

83. Mahajan, J. R.; Resck, I. S.; J. Braz. Chem. Soc. 1997, 8, 603 e referências aí citadas.

84. Hanaki, N.; Ishihara, K.; Kaino, M.; Naruse, Y.; Yamamoto, H.; Tetrahedron 1996, 52, 7297.

85. Martel, A.; Maisonneuve, V.; Brown, E.; Dujardin, G.; Synthesis 2003, 539.

86. Hatcher, M. A.; Borstnik, K.; Posner, G. H.; Tetrahedron Lett. 2003, 44, 5407.

87. Posner, G. H.; Hatcher, M. A.; Maio, W. A.; Org. Lett. 2005, 7, 4301

88. Ferraz, H. M. C.; Longo Jr., L. S.; Org. Lett. 2003, 5, 1337.

89. Bakke, J. M.; Frohaug, A. E.; J. Phys. Org. Chem. 1996, 9, 310.

90. Silva, R. S. F.; Guimarães, T. T.;Teixeira, D. V.; Lobato, A. P. G.; Pinto, M C. F. R.; Simone, C. A.; Soares, J. G.; Cioletti, A. G.; Goulart, M. O. F.; Pinto, A. V.; J. Braz. Chem. Soc. 2005, 16, 1074.

91. Nubbemeyer, U.; Synthesis 2003, 961.

92. Gonda, J.; Angew. Chem., Int. Ed. 2004, 43, 3516.

93. Burton, J. W.; Clarck, J. S.; Derrer, S.; Stork, T. C.; Bendall, J. G.; Holmes, A. B.; J. Am. Chem. Soc. 1997, 119, 7483.

94. Harrison, J. R.; Holmes, A. B.; Collins, I.; Synlett 1999, 972.

95. Burton, J. W.; O’Sullivan, P. T.; Anderson, E. A.; Holmes, A. B.; Collins, I.; Chem. Comm. 2000, 631

96. Anderson, E. A.; Holmes, A. B.; Collins, I.; Tetrahedron Lett. 2000, 41, 117

97. Anderson, E. A.; Davidson, J. E. P.; Harrison, J. R.; O’Sullivan, P. T.; Burton, J. W.; Collins, I.; Holmes, A. B.; Tetrahedron, 2002, 58, 1943.

98. O’Sullivan, P. T.; Buhr, W.; Fuhry, M. A. M.; Harrison, J. R.; Davies, J. E.; Feeder, N.; Marshall, D. R.; Burton, J. W.; Holmes, A. B.; J. Am. Chem. Soc. 2004, 126, 2194.

99. Deagostino, A.; Maddaluno, J.; Prandi, C.; Venturello, P.; J. Org. Chem. 1996, 61, 7597

100. Deagostino, A.; Maddaluno, J.; Mella, M.; Prandi, C.; Venturello, P.; J. Chem. Soc. Perkin Trans. I 1998, 881.

101. Lemiègre, L.; Stevens, R. L.; Combret, J. C.; Maddaluno, J.; Org. Biomol. Chem. 2005, 3, 1308

102. Ferraz, H. M. C.; Longo Jr., L. S.; resultados não publicados. 